\title{
Understanding atomic-scale phase separation of liquid Fe-Cu alloy
}

\author{
WANG HaiPeng \& WEI BingBo* \\ Department of Applied Physics, Northwestern Polytechnical University, Xi'an 710072, China
}

Received June 25, 2011; accepted July 29, 2011

\begin{abstract}
Using liquid $\mathrm{Fe}_{60} \mathrm{Cu}_{40}$ alloy as a model, the structure of liquid $\mathrm{Fe}-\mathrm{Cu}$ alloy systems is investigated in the temperature range 1200-2200 K, covering a large metastable undercooled regime, to understand the phase separation of liquid Fe-Cu alloys on the atomic scale. The total pair distribution functions (PDFs) indicate that liquid $\mathrm{Fe}_{60} \mathrm{Cu}_{40}$ alloy is ordered in the short range and disordered in the long range. If the atom types are ignored, the total atom number densities and PDFs demonstrate that the atoms are distributed homogenously in the liquid alloy. However, the segregation of $\mathrm{Fe}$ and $\mathrm{Cu}$ atoms is very obvious with decreasing temperature. The partial PDFs and coordination numbers show that the $\mathrm{Cu}$ and $\mathrm{Fe}$ atoms are not apt to get together on the atomic scale at low temperatures; this will lead to large fluctuations and phase separation in liquid $\mathrm{Fe}-\mathrm{Cu}$ alloy.
\end{abstract}

liquid alloy, phase separation, atomic scale, Fe-Cu alloy, undercooling

Citation: Wang H P, Wei B B. Understanding atomic-scale phase separation of liquid Fe-Cu alloy. Chinese Sci Bull, 2011, 56: 3416-3419, doi: 10.1007/s11434011-4739-x

Phase separation frequently occurs in various systems, including colloids, liquid crystals, and metal alloys. This has aroused great research interest in the field of condensedmatter physics in recent years [1-6]. In metal alloy systems, liquid phase separation is always characteristic of monotectic and peritectic alloys such as $\mathrm{Al}-\mathrm{Pb}, \mathrm{Fe}-\mathrm{Sn}, \mathrm{Fe}-\mathrm{Cu}$, and $\mathrm{Co}-\mathrm{Cu}$ alloys [7-9]. For this type of alloy, it is usually hard to achieve high undercooling before nucleation of secondary droplets because of the low liquid-liquid interface energy. This causes great difficulties in the study of phase separation at high undercoolings. It is also difficult to directly observe the phase separation in situ because of the opacity and metastability of the alloys. Although experimental observations can be achieved in some transparent solutions, the scale is always at the micrometer level. It is desirable to understand the phase separation on the atomic scale.

To date, there have been extensive investigations on the phase separation of metal alloys, and most research has focused on investigating the solidified microstructures experimentally or by simulation $[10,11]$. It has been shown that core-shell microstructures form within $\mathrm{Fe}-\mathrm{Co}-\mathrm{Cu}$ and

*Corresponding author (email: bbwei@nwpu.edu.cn)
Fe-Sn alloy droplets solidified during free fall $[12,13]$. The phase-separation processes in $\mathrm{Fe}-\mathrm{Cu}$ and $\mathrm{Ni}-\mathrm{Cu}-\mathrm{Pb}$ alloys have been simulated by field methods. It has been shown that the $\mathrm{Cu}$ - or $\mathrm{Pb}$-rich phase always forms the outer layer because of surface segregation, whereas internal microstructural evolution is mainly controlled by Marangoni convection $[14,15]$. In contrast, much work remains to be done in understanding atomic-scale phase separation. The serious experimental difficulties encountered on the atomic scale have resulted in atomic-scale phase-separation mechanisms being less well understood. Changes in liquid structure are therefore of great importance for clarifying the kinetics of phase separation. Molecular dynamics (MD) calculations combined with a reasonable potential model have served as a powerful tool for studying the structures of liquid alloys [16-18].

$\mathrm{Fe}-\mathrm{Cu}$ alloy is a typical peritectic alloy system, and involves repulsive interactions between $\mathrm{Fe}$ and $\mathrm{Cu}$. Its liquid alloy always separates into two liquids when the temperature decreases below its liquidus temperature because of a metastable immiscible gap in the phase diagram. Although various studies of the phase separation of $\mathrm{Fe}-\mathrm{Cu}$ alloys have already been performed, it is still an appropriate model sys- 
tem for exploring atomic-scale phase separation. Using $\mathrm{Fe}_{60} \mathrm{Cu}_{40}$ alloy as the research subject, the purpose of this work is to reveal the atomic distribution in liquid $\mathrm{Fe}-\mathrm{Cu}$ alloys, using MD calculations, to further understand atomicscale phase-separation mechanisms.

MD calculations were performed to study the liquid structure of Fe-Cu alloys. The MEAM model was used because it is valid for both fcc and bcc alloys [19,20]; this is described in more detail by Baskes [21]. In the model, $19200 \mathrm{Fe}$ atoms and $12800 \mathrm{Cu}$ atoms are arranged in a cubic box under a constant-pressure and constant-temperature (NPT) ensemble; the ensemble is subject to periodic boundary conditions. The temperature is adjusted every 50 steps. The pressure is set to 1 bar to simulate real conditions. The time step is $1 \mathrm{fs}$. To obtain the equilibrium liquid state, the calculation starts at $3000 \mathrm{~K}$, and is kept constant for 200000 steps. A cooling process with a $10^{13} \mathrm{~K} / \mathrm{s}$ cooling rate is performed for calculations at $100 \mathrm{~K}$ temperature intervals. At each temperature, 100000 steps are carried out to obtain equilibrium. The last 50000 steps are used to calculate the final results. All codes (LAMMPS) are run in a Lenovo 1800 Cluster system.

To examine the state of the calculated cell at every calculated temperature, the pair distribution function (PDF) is computed by the expression $g(r)=V<n_{i}(r, r+\Delta r)>$ I $\left(4 \pi r^{2} \Delta r N\right)$, where $V$ is the calculated cell volume, $n_{i}(r, r+$ $\Delta r)$ is the atom number around the $i$ th atom in a spherical shell between $r$ and $r+\Delta r,\langle\cdots\rangle$ is the average symbol, and $N$ is the atom number. The temperature range for the liquid structure is $1200-2200 \mathrm{~K}$, including both a superheating range and a large metastable undercooled regime. Figure 1 presents the PDF results for $\mathrm{Fe}_{60} \mathrm{Cu}_{40}$ alloy; these results suggest that the atomic structure is ordered in the short range and disordered in the long range, even at the lowest temperature of $1200 \mathrm{~K}$. By combining with the mean-square displacement versus time, it can be concluded that $\mathrm{Fe}_{60} \mathrm{Cu}_{40}$ alloy is a highly metastable liquid below its liquidus temperature of $1706 \mathrm{~K}$, rather than a solid.

Although the total atomic distribution of the $\mathrm{Fe}_{60} \mathrm{Cu}_{40}$ alloy can be deduced from Figure 1, the distribution of Fe and $\mathrm{Cu}$ atoms is not clear. Whether phase separation occurs is therefore unknown, and the distribution of the atom number density is calculated to clarify this point. The simulated cell is divided into slabs of thickness $1 \AA$, and the atom number is statistically averaged in each slab, as shown in Figure 2. In each part of the figure there are three curves: the atom number density for $\mathrm{Fe}$ atoms, for $\mathrm{Cu}$ atoms, and for all the atoms. For all four temperatures studied, the atom number densities for all the atoms are almost flat; this shows that the atoms distribute homogenously in the liquid alloy if the atom types are not discriminated.

Figure 2 also displays the distribution of different atoms at various temperatures. For the cases of $2200 \mathrm{~K}$ (Figure 2(a)) and $1800 \mathrm{~K}$ (Figure 2(b)), the atom number densities of $\mathrm{Fe}$ and $\mathrm{Cu}$ atoms fluctuate slightly around their average

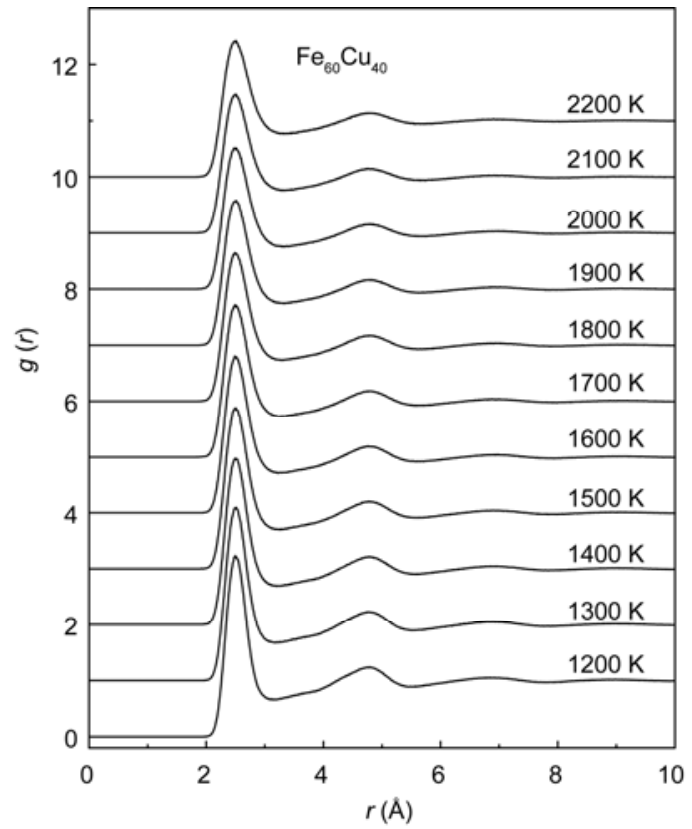

Figure 1 Pair distribution functions of liquid $\mathrm{Fe}_{60} \mathrm{Cu}_{40}$ alloy. These indicate that $\mathrm{Fe}-\mathrm{Cu}$ alloys are ordered in the short range and disordered in the long range.
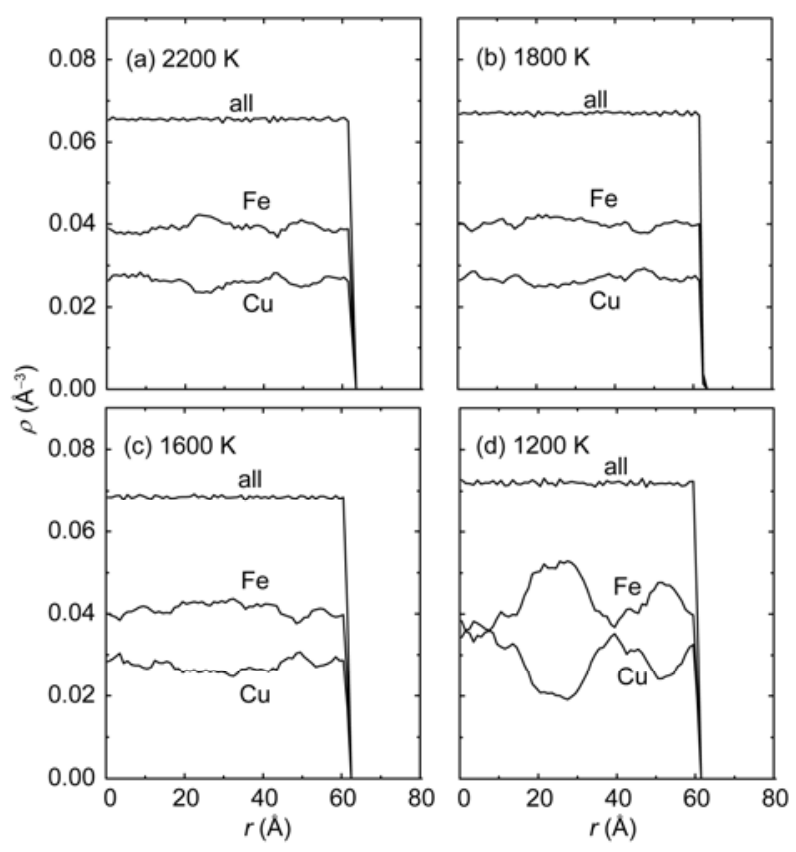

Figure 2 Atom number density profiles along the $x$-axis of liquid $\mathrm{Fe}_{60} \mathrm{Cu}_{40}$ alloy at $2200 \mathrm{~K}$ (a), $1800 \mathrm{~K}$ (b), $1600 \mathrm{~K}$ (c), and $1200 \mathrm{~K}$ (d).

values at different positions. This means that no phase separation occurs in liquid $\mathrm{Fe}_{60} \mathrm{Cu}_{40}$ alloy because these temperatures are higher than the liquidus temperature of $1706 \mathrm{~K}$. The binodal line in the experiment is about $100 \mathrm{~K}$ lower than this temperature, i.e. around $1600 \mathrm{~K}$. For the case below the binodal line at $1600 \mathrm{~K}$ (Figure 2(c)), the fluctuations of the atom number densities of $\mathrm{Fe}$ and $\mathrm{Cu}$ become 
larger than those at $2200 \mathrm{~K}$ (Figure 2(a)) and $1800 \mathrm{~K}$ (Figure 2(b)). When the temperature falls to $1200 \mathrm{~K}$ (Figure 2(d)), the fluctuations are extremely serious. For Fe atoms, the atom number density at the $30 \AA$ position is about $25 \%$ larger than its average value. For $\mathrm{Cu}$ atoms, the atom number density at the $30 \AA$ position is about $30 \%$ lower than its average value. The width of this serious fluctuation is about $20 \AA$. A similar situation occurs in the $45-55 \AA$ range. Although complete phase separation does not occur, i.e. some $\mathrm{Cu}$ atoms are still in the Fe-rich zone and some $\mathrm{Fe}$ atoms are still in the $\mathrm{Cu}$-rich zone, the segregation of $\mathrm{Fe}$ and $\mathrm{Cu}$ atoms is significant. The above results were calculated along the $x$-axis. We also examined the results along the $y$-axis and the $z$-axis, and the situations were similar. Accordingly, we can speculate that the same types of atom begin to segregate when the temperature is below a critical value. In particular, the segregation becomes increasingly pronounced with decreasing temperature.

To further understand this phenomenon on the atomic scale, partial PDFs are calculated to illustrate the atomic short-range degree of order for $\mathrm{Fe}$ and $\mathrm{Cu}$ atoms, as shown in Figure 3. The $g_{\mathrm{Fe}-\mathrm{Fe}}$ represents the results by calculating the PDF and ignoring the existence of $\mathrm{Cu}$ atoms; $g_{\mathrm{Cu}-\mathrm{Cu}}$ represents the results by calculating the PDF and ignoring the existence of $\mathrm{Fe}$ atoms. Setting a random $\mathrm{Fe}$ or $\mathrm{Cu}$ atom as the center, $g_{\mathrm{Fe}-\mathrm{Cu}}$ is obtained by calculating the PDF of only $\mathrm{Cu}$ atoms around this $\mathrm{Fe}$ atom, or only $\mathrm{Fe}$ atoms around this $\mathrm{Cu}$ atom. For the partial PDFs of $g_{\mathrm{Fe}-\mathrm{Fe}}$ and $g_{\mathrm{Cu}-\mathrm{Cu}}$, the curves at $2200 \mathrm{~K}$ (Figure 3(a)) and $1800 \mathrm{~K}$ (Figure 3(b)) almost overlap. If the temperature is lower than $1800 \mathrm{~K}, g_{\mathrm{Cu}-\mathrm{Cu}}$ is larger than $g_{\mathrm{Fe}-\mathrm{Fe}}$ when $r<10 \AA$. This is particularly noticeable at the lowest temperature of $1200 \mathrm{~K}$ (Figure 3(d)).
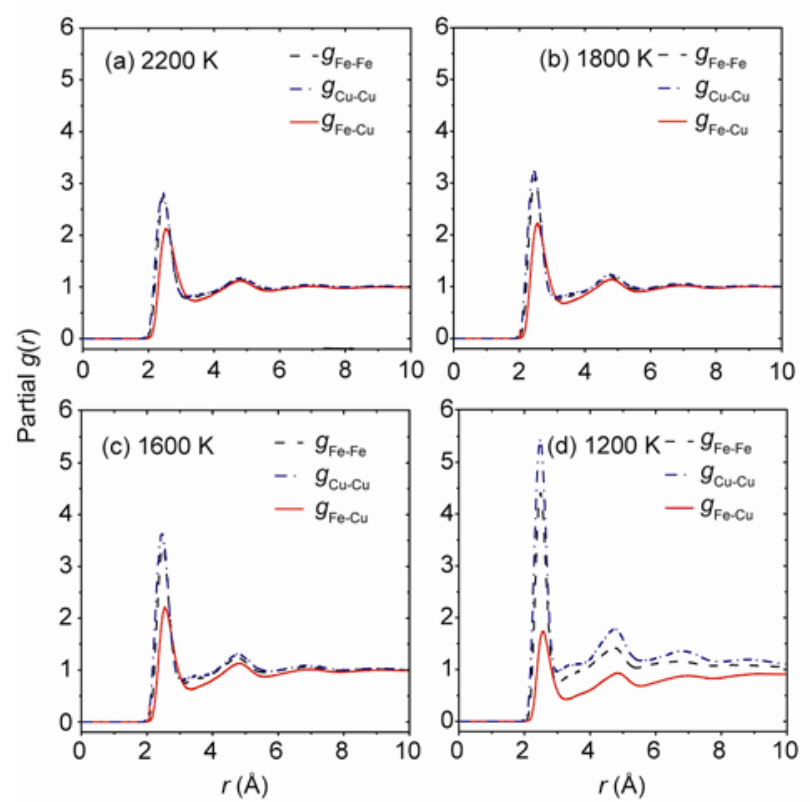

Figure 3 Partial pair distribution functions of liquid $\mathrm{Fe}_{60} \mathrm{Cu}_{40}$ alloys at $2200 \mathrm{~K}$ (a), $1800 \mathrm{~K}$ (b), $1600 \mathrm{~K}$ (c), and $1200 \mathrm{~K}$ (d).
With decreasing temperature, the heights of the first peaks increase; these peaks represent the short-range degree of order at the first-neighbor distance. The first-peak value of $g_{\mathrm{Cu}-\mathrm{Cu}}$ is 2.8 at $2200 \mathrm{~K}$, and it increases to 5.5 when the temperature drops to $1200 \mathrm{~K}$, i.e. the value at $1200 \mathrm{~K}$ is almost twice that at $2200 \mathrm{~K}$. Moreover, the first-peak value of the total PDF of this alloy is only 3.2 at $1200 \mathrm{~K}$. The order degree of the $\mathrm{Cu}$ atoms is much larger than the average value. The value of $g_{\mathrm{Fe}-\mathrm{Cu}}$ is always smaller than $g_{\mathrm{Cu}-\mathrm{Cu}}$ and $g_{\mathrm{Fe}-\mathrm{Fe}}$, and is also smaller than the average PDF of this alloy. With decreasing temperature, this effect becomes increasingly serious. When the temperature is higher than $1600 \mathrm{~K}$, $g_{\mathrm{Fe}-\mathrm{Cu}}$ does not fluctuate around 1 until $r$ exceeds $6 \AA$. Once the temperature has decreased to $1200 \mathrm{~K}, g_{\mathrm{Fe}-\mathrm{Cu}}$ is always smaller than 1 until $r$ increases to $10 \AA$. Moreover, the first-peak value of $g_{\mathrm{Fe}-\mathrm{Cu}}$ decreases with decreasing temperature, suggesting that the order degree between $\mathrm{Fe}$ and $\mathrm{Cu}$ atoms decreases at much lower temperatures.

According to the above analysis, it can be inferred that $\mathrm{Cu}$ atoms "like" to be the neighbors of $\mathrm{Cu}$ atoms and $\mathrm{Fe}$ atoms "like" to be the neighbors of Fe atoms. Fe atoms are not "willing" to be the neighbors of $\mathrm{Cu}$ atoms. This leads to the main difference in the partial PDFs. To further confirm this point, the coordination numbers of $\mathrm{Fe}$ and $\mathrm{Cu}$ are statistically obtained, and they are listed in Table 1 . At a high temperature, the coordination number $N$ between $\mathrm{Fe}$ and $\mathrm{Cu}$ atoms is similar to that for normal mixing. For instance, the $N$ of $\mathrm{Cu}$ surrounded by $\mathrm{Fe}$ atoms ( $\mathrm{Cu}$ atoms are not counted) is 5.24 at $2200 \mathrm{~K}$, which is close to the value of 4.06 for $N_{\mathrm{Cu}-\mathrm{Cu}}$. In the case of a low temperature, both $N_{\mathrm{Fe}-\mathrm{Cu}}$ and $N_{\text {Cu-Fe }}$ decrease noticeably. At $1200 \mathrm{~K}$, the values of $N_{\mathrm{Fe}-\mathrm{Cu}}$ and $N_{\mathrm{Cu}-\mathrm{Fe}}$ are 2.20 and 3.30; these are much smaller than the values of 7.05 and 6.14 for $N_{\mathrm{Fe}-\mathrm{Fe}}$ and $N_{\mathrm{Cu}-\mathrm{Cu}}$. From the coordination number perspective, the $\mathrm{Cu}$ atom number around $\mathrm{a} \mathrm{Cu}$ atom and the $\mathrm{Fe}$ atom number around a $\mathrm{Fe}$ atom are larger than those for coordination of atoms of different types. This also indicates that the segregation of $\mathrm{Fe}$ and $\mathrm{Cu}$ atoms leads to large fluctuations in the atom number densities, although they do not separate completely because the coordination numbers are still larger than zero.

In summary, the liquid structure of $\mathrm{Fe}_{60} \mathrm{Cu}_{40}$ alloy is studied in the light of its dependence on temperature to understand the atomic-scale phase-separation mechanism. The

Table 1 Coordination number of $\mathrm{Fe}$ atoms and $\mathrm{Cu}$ atoms ${ }^{\text {a) }}$

\begin{tabular}{ccccccc}
\hline$T(\mathrm{~K})$ & $N_{\mathrm{Fe}}$ & $N_{\mathrm{Fe}-\mathrm{Fe}}$ & $N_{\mathrm{Fe}-\mathrm{Cu}}$ & $N_{\mathrm{Cu}}$ & $N_{\mathrm{Cu}-\mathrm{Fe}}$ & $N_{\mathrm{Cu}-\mathrm{Cu}}$ \\
\hline 1200 & 9.25 & 7.05 & 2.20 & 9.44 & 3.30 & 6.14 \\
1600 & 9.31 & 6.14 & 3.17 & 9.38 & 4.76 & 4.63 \\
1800 & 9.34 & 5.99 & 3.35 & 9.30 & 5.03 & 4.27 \\
2200 & 9.39 & 5.90 & 3.50 & 9.31 & 5.24 & 4.06
\end{tabular}

a) $T$ is temperature; $N_{\mathrm{Fe}}, N_{\mathrm{Fe}-\mathrm{Fe}}, N_{\mathrm{Fe}-\mathrm{Cu}}, N_{\mathrm{Cu}}, N_{\mathrm{Cu}-\mathrm{Fe}}, N_{\mathrm{Cu}-\mathrm{Cu}}$ are the coordination numbers of $\mathrm{Fe}$, Fe surrounded by $\mathrm{Fe}$ atoms, $\mathrm{Fe}$ surrounded by $\mathrm{Cu}$ atoms, $\mathrm{Cu}, \mathrm{Cu}$ surrounded by $\mathrm{Fe}$ atoms, and $\mathrm{Cu}$ surrounded by $\mathrm{Cu}$ atoms. 
total PDFs indicate that the atomic structure is ordered in the short range and disordered in the long range at all the investigated temperatures. The atoms are distributed homogenously in the liquid alloy if the atom types are not differentiated. However, with decreasing temperature, the segregation of $\mathrm{Fe}$ and $\mathrm{Cu}$ atoms is remarkable in terms of the atom number densities of the $\mathrm{Fe}$ and $\mathrm{Cu}$ atoms. Although complete phase separation does not occur, the partial PDFs and the coordination numbers confirm that atoms of the same type display a strong tendency to get together. These results provide some fundamental insights into the understanding of atomic-scale phase separation.

The authors are grateful to Mr. Jian Chang, Mr. Baokun Lu, and Mr. Shangjiang Yang for their helpful discussions. This work was supported by the National Natural Science Foundation of China (50971103 and 50971105), the Program for New Century Excellent Talents, Natural Science Foundation of Shaanxi Province (2010JQ6004), Shaanxi Project for Young New Star in Science and Technology, and NPU Foundation for Fundamental Research.

1 Boamfa M I, Kim M W, Maan J C, et al. Nature, 2003, 421: 149-152
2 Greaves G N, Wilding M C, Fearn S, et al. Science, 2008, 322: 566-570

3 Cao X A, Yang Y. Appl Phys Lett, 2010, 96: 151109

4 Kim C, Kang D M, Lee T Y, et al. Appl Phys Lett, 2009, 94: 193504

5 Braicovich L, van den Brink J, Bisogni V, et al. Phys Rev Lett, 2010, 104: 077002

6 Hong Z Y, Lu Y J, Xie W J, et al. Chinese Sci Bull, 2007, 52: 1446-1450

7 Reith D, Podloucky R. Phys Rev B, 2009, 80: 054108

8 Kolli R P, Seidman D N. Acta Mater, 2008, 56: 2073-2088

Park B J, Chen Y M, Ohkubo T. Intermetallics, 2009, 17: 958-961

10 Yuge K, Seko A, Tanaka I, et al. Phys Rev B, 2005, 72: 174201

11 Koziel T, Kedzierski Z, Zielinska-Lipiec A, et al. Scripta Mater, 2006, 54: 1991-1995

12 Dai F P, Wei B B. Chinese Sci Bull, 2009, 54: 1287-1294

13 Luo B C, Liu X R, Wei B B. J Appl Phys, 2009, 106: 053523

14 Luo B C, Wang H P, Wei B B. Chinese Sci Bull, 2009, 54: 183-188

15 Qin T, Wang H P, Wei B B. Sci China Ser G-Phys Mech Astron, 2007, 50: 546-552

16 Barabash S V, Ozolins V, Wolverton C. Phys Rev Lett, 2008, 101: 155704

17 Gee R H, Lacevic N, Fried L E. Nat Mater, 2006, 5: 123

18 Wang H P, Chang J, Wei B B. J Appl Phys, 2009, 106: 033506

19 Sun Y L, Shen J, Valladares A A. J Appl Phys, 2009, 106: 073520

20 Gheribi A E. Mater Chem Phys, 2009, 116: 489-496

21 Baskes M I. Phys Rev B, 1992, 46: 2727-2742

Open Access This article is distributed under the terms of the Creative Commons Attribution License which permits any use, distribution, and reproduction in any medium, provided the original author(s) and source are credited. 